\title{
A(HO)RMAR LA LENGUA DEL POEMA: ÁNGEL GONZÁLEZ 0 LA DINÁMICA DEL CÓDIGO
}

\author{
SHAPING THE LANGUAGE OF \\ THE POEM: ÁNGEL GONZÁLEZ OR \\ THE DYNAMICS OF THE POETIC CODE
}

\author{
Claude Le Bigot \\ Université Rennes 2
}

Resumen: Este artículo pretende examinar la evolución del lenguaje poético de Ángel González, especialmente la transición desde los modelos codificados dentro de una tradición bien asentada (lira, canción, romance, soneto, elegía) hasta una subversión de las formas que, si bien se emparentan con el versolibrismo, mantienen lazos con lo canónico, no haciendo más que duplicar recursos surgidos con la modernidad: versos escalonados, sangrados, guiones. Todo lo que permite agujerear el texto es también portador de ritmo. La oposición medida / encabalgamiento, factor tensional de antiguo abolengo, se regenera bajo la pluma de Ángel González, al lado de otros procedimientos sintácticos, para crear una voz propia en la que se interpenetran lo culto y lo popular. Existe en Ángel González una forma de oralidad, inseparable del ritmo, como articulación de un hablante con su decir.

Palabras clave: Ángel González; formas codificadas; ritmo; signos gráficos; versolibrismo.

ABSTRACT:This contribution proposes to examine the evolution of poetic language in Ángel González's works, in particular the transition from models codified by a long-established tradition (lira, ballad, romance, sonnet, elegy) to a subversion of forms which - although it is akin to free verse- still borrows from the canonical form and seeks to tap literary processes born of modernity: stepped lines, blank spaces, dashes. Anything that allows to space out the text becomes a constitutive element of rhythm. Under Ángel González's pen, new life is breathed into the antithesis between beat and enjambment, a long-established source of tension, revisited thanks to other syntactic devices so as to create an idiosyncratic voice commingling the erudite and the popular. A form of orality exists in Ángel 
González which is inseparable from rhythm as articulation between the poetic voice and its spoken word.

KEY words:Ángel González; canonical forms; rhythm; typographic signs; free verse.

La poesía de Ángel González no suele considerarse como ejemplo de emancipación formal con rupturas atrevidas como las potenciadas por las vanguardias o las neovanguardias. Sin embargo, cualquier lector atento de su obra se dará cuenta de que el abandono de las formas tradicionales se produce tempranamente en beneficio de una versificación llamada libre, porque no se ajusta al cómputo silábico exacto, incluso cuando aúna una sutil polimetría. Aquella idea corresponde a una visión armoniosa del universo que no tiene cabida en la poesía gonzaliana. Fue, por supuesto, Ángel González el testigo de un tiempo sombrío, marcado por la derrota moral de una población amordazada por el régimen franquista. Sus primeros poemarios llevan las huellas de una preocupación social ampliamente señalada y estudiada por la crítica. Pero lo que no se comentó suficientemente fue cómo el poeta plasmó la mediocridad ambiental en una forma no tan alejada del lenguaje común, y que cultivaba sin embargo las múltiples potencialidades de la lengua cotidiana. Ángel González se las arreglaba para poner en tensión un idioma liberado de lo excesivamente pulido, ordenado y armonioso, tal como lo exigiera una estética sometida al culto de la belleza pura. La poesía a la que se adscribe Ángel González en la década de los 60 cuestiona una doxa que quisiera limitar el arte poético a una forma de lenguaje pulcro o en rebeldía contra la lengua ordinaria. En la mente de Ángel González, expresarse en verso no significa entregarse a un ajuste métrico del lenguaje, sino organizar un espacio desde el cual el ser evalúa la medida de su acabamiento. No sería absurdo decir que se establece una correspondencia entre el compás rítmico de la lengua y la dimensión ontológica de la escritura. Entendámonos: el poeta siempre tiene que resolver los antagonismos entre su percepción del mundo y la representación que de este pretende plasmar en sus poemas. De este dilema nace el ritmo propio de la escritura poética. Como dijo el poeta y crítico Jean-Michel Maulpoix:

La poesía es en gran parte esta escritura con cesuras que comunica a la escansión rítmica un valor de subrayado: 
aquella aísla, destaca o encadena y dota de mayor visibilidad el lenguaje que se torna entonces en cuestión de energía, tributaria de intensidades que algunos metaforizan a veces como eléctricas» (2018: 100).

Lejos de un ambiente a lo Mallarmé, tampoco tentado por los malabarismos caligramáticos de un Apollinaire, Ángel González acude sin embargo a varios procedimientos que crean ritmos inesperados con cesuras poco habituales que acaban por conformar pautas rítmicas portadoras de modernidad. Entre los recursos creadores de discontinuidad, hay que contar, junto a los factores tensionales de antiguo abolengo como el encabalgamiento, otros muy usados por Ángel González como los guiones, el entrecomillado, los paréntesis, los versos escalonados, los sangrados... O sea, una serie de signos visuales que zarandean la cohesión textual sin llegar a la subversión sintáctica. Pero este proceder, en nuestra opinión, es revelador de una actitud compleja frente al mundo cuya percepción integra las tensiones entre lo continuo y lo discontinuo, lo mismo y lo diferente, la yuxtaposición y la oposición. Intentaremos mostrar que el uso de estos signos visuales, con incidencias en la sintagmática del texto, participa de una dinámica paradójica: la revelación del ser en su continuidad necesita las rasgaduras del discurso.

\section{DESDE EL DESPIECE DE LA}

FORMA CONVENCIONAL HASTA EL SURGIMIENTO DEL VERSO LIBRE

En sus primeros poemarios (Áspero mundo y Sin esperanza, con convencimiento), Ángel González fue bastante fiel a las formas convencionales como sonetos, canciones, décimas (muy pocas y alejadas ya del molde tradicional), romances, romancillos, con una preferencia acaso por todo lo que permite la mayor fluidez del ritmo. Pero su interés por una mayor flexibilidad del discurso lo llevará pronto al cultivo de una amplia polimetría, hasta desprenderse progresivamente de todo lo llamativo que conlleva la uniformidad del metro o la rima sonora y efectista. Además, atraído por la naturalidad de la expresión, siempre buscó Ángel González la adecuación entre el contenido y su plasmación formal para evitar un alarde estetizante que hubiera entrado en contradicción con las intenciones críticas 
que el autor asignaba a la poesía. En su ensayo La poesía de Ángel González, Emilio Alarcos Llorach hablaba de un «ritmo del contenido [que] le obligaba a forjarse una expresión rítmica particular que no traicione a los contenidos que se manifiestan» (1996: 66). El sagaz crítico nos enseñó a considerar que el gusto cada vez más afirmado de Ángel González por una polimetría variada en una misma composición hasta la adopción del verso libre fue una opción estética para conseguir una prosodia más adecuada a los contenidos; o sea, una vinculación más fuerte entre la forma y el sentido.

Sin embargo, la permanencia de pautas rítmicas heredadas de la métrica clásica es patente, como señaló Alarcos Llorach (1996: 66-71) apoyándose en el análisis del poema «Domingo». Se podría observar con otro ejemplo perteneciente a Áspero mundo (González, 1986: 31) la tentación de deconstruir las pautas métricas convencionales en provecho de un nuevo orden prosódico mejor adaptado a la expresividad rítmica que el poeta persigue. Distribuidos según una métrica regular, notamos la persistencia del endecasílabo, habida cuenta de las sinalefas y un hiato. Así quedarían tan solo tres versos fuera de la isometría (vv. 6, 8 y 11). Reescribimos el texto de la siguiente manera:

Mientras tú existas, mientras mi mirada te busque más allá de las colinas, mientras nada

5 me llene el corazón, si no es tu imagen, y haya una remota posibilidad de que estés viva en algún sitio, iluminada por una luz — cualquiera...

yo presienta que eres y te llamas así, con este nombre tuyo $\tan$ pequeño seguiré como ahora, amada

15 mía,

transido de distancia,

bajo este amor que crece y no se muere, bajo este amor que sigue y nunca acaba.
Mientras tú existas, mientras mi mirada (11) te busque más allá de las colinas, (11) mientras nada me llene el corazón, (11) si no es tu imagen, y haya una remota (11) posibilidad de que / estés viva (end. con hiato)

* en algún sitio, iluminada (9) por una luz — cualquiera... Mientras yo (11)

^ presienta que eres y te llamas así, (12) con este nombre tuyo tan pequeño (11) seguiré como ahora, amada mía, (11)

$\star$ transido de distancia, (7) bajo este amor que crece y no se muere, (11) bajo este amor que sigue y nunca acaba. (11)

Si comparamos con la versión final publicada, ¿qué ventajas obtuvo Ángel González del despiece del endecasílabo? En primer lugar, descomponer una organización sintáctica que había conocido su época de esplendor durante el Renacimiento y siglos posteriores 
hasta el Romanticismo, ya que el poema gonzaliano no deja de recordar la famosa rima IV de G. A. Bécquer. Luego, para marcar los dos polos del sentimiento amoroso, Ángel González se hace con la plasticidad del significante, que permite recalcar la condición de existencia de un sujeto distante: «Mientras tú existas» se opone al «Mientras / yo presienta»; la conjunción está puesta de relieve con un verso escalonado, dejando con el encabalgamiento el pronombre de primera persona en posición inicial del verso siguiente. El poeta reduplica el efecto tensional con la cesura "amada / mía».Y marca otra vez la distancia entre el amante y la amada, pese a acudir a la redundancia («transido de distancia»). La tópica de la poesía amatoria se amolda a una métrica variada que sabe aprovechar las disyuntivas del verso breve.

El versolibrismo que combina el endecasílabo con versos de arte menor — sobre todo con los muy breves - es factor de tensión. Se podría comprobar semejante efecto en el poema «Otro tiempo vendrá distinto a este», en el cual el locutor en primera persona se opone a otro que lo recrimina por su explícito rechazo de las posturas idealistas:

Otro tiempo vendrá distinto a este.

$\mathrm{Y}$ alguien dirá:

«Hablaste mal. Debiste haber contado

otras historias:

violines estirándose indolentes

en una noche densa de perfumes,

bellas palabras calificativas

para expresar amor ilimitado,

amor al fin sobre las cosas

todas».

Pero hoy,

cuando es la luz del alba

como la espuma sucia

de un día anticipadamente inútil, estoy aquí,

insomne, fatigado, velando

mis armas derrotadas,

y canto

todo lo que perdí: por lo que muero

(González, 1986: 63). 
En un texto que se abre con el ritmo de los endecasílabos casi uniformemente (vv. 1, 3, 5, 6, 7 y 8; incluso el v. 9, ya que forma un endecasílabo al enlazar «cosas» $\mathrm{y}$ «todas»), la segunda estrofa rompe esta pauta con segmentos brevísimos que condensan todo el significado del contenido: «Pero hoy... / estoy aquí... / y canto...». La idea que defiende Ángel González se contrapone a la de su interlocutor, que intenta atraerlo hacia una concepción estetizante de la poesía, cuando lo que motiva la postura moral defendida por un poeta solitario y agotado son sus "armas derrotadas». En este poema inicial de Sin esperanza, con convencimiento, se diseña una ética del desaliento apoyada en una prosodia de la fragmentación métrica. El famoso «despiece» apuntado por Alarcos Llorach se confirma como búsqueda de una adecuación natural entre forma y contenido. Pero discrepamos de las conclusiones del crítico cuando escribe: «basta para convencerse de que, con métrica tradicional o métrica más libre, la intención del poeta es la misma: aprovechar el ritmo métrico de manera que vaya acorde con el ritmo de contenido que comunica» (1996: 78). Al contrario, diríamos que la fragmentación métrica contribuye mejor a la creación de un espacio disfórico que la armonía fónica tendería a ocultar. La única contención que manifiesta Ángel González desemboca en una escritura que roza los límites sin transgredirlos con una violencia hecha contra la lengua. Naturalidad, sencillez, legibilidad siguen siendo criterios invulnerables. Como el poeta no quiere despistar a sus lectores con audacias agramaticales, se encamina hacia otros recursos de "desfamiliarización», descubriendo en técnicas de rupturas sintácticas «suaves» modulaciones expresivas singulares y suficientemente eficaces para generar una gramática del fraseo.

\section{HACIA UNA GRAMÁTICA DEL FRASEO}

Entre los recursos convocados por Ángel González en la búsqueda de un ritmo nuevo, cabe una serie de procedimientos que afectan el régimen prosódico del texto, como los guiones, los paréntesis, el entrecomillado, los sangrados y los versos escalonados. Examinemos primero la presencia frecuente de los guiones, que ocupan en Ángel González un lugar destacado. En la mayoría de las ocasiones, acude Ángel González a los guiones para marcar una intensidad afectiva o apuntar un juicio metadiscursivo sobre su propio enunciado; pero 
ocurre también, otras veces, que su presencia no sirve más que para introducir el cambio de enunciador, que es el empleo normal en los textos en prosa con diálogos. La décima siguiente, tomada de Áspero mundo, alejada ya del modelo canónico, reúne dos usos distintos de los guiones (doble o aislado):

Voz que soledad sonando por todo el ámbito asola, de $\tan$ triste, de tan sola, todo lo que va tocando.

Así es mi voz cuando digo - de tan solo, de tan tristemi lamento que persiste bajo el cielo y sobre el trigo.

- ¿Qué es eso que va volando?

- Solo soledad sonando (González, 1986: 29).

En el primer ejemplo, el poeta quiere materializar el sentimiento de soledad que lo abruma, pero soledad necesaria para que surja el canto. El sintagma "digo mi lamento» lleva en su centro el inciso «-de tan solo, de tan triste-». Esta voz de dentro es el surgimiento mismo del lirismo, que deja al poeta una sensación de insaciable deseo de elevarse mediante el lenguaje. A continuación, el guion aislado solamente indica el cambio de enunciador, aunque este caso puede corresponder a la voz del poeta que se interroga a sí mismo. El último verso, carente de verbo, puede interpretarse como desdoblamiento del locutor principal que capta el eco de su canto, condenado a repetirse sin cesar. En realidad, el sistema dialógico mimetiza el eco de un silencio. Los guiones no modifican la escansión octosilábica, pero instauran la discontinuidad de lo real y apuntan la condición de «desterrado» del poeta ${ }^{1}$.

1 Cabe aportar tal vez una definición del lirismo moderno que Ángel González encarna a través de este breve poema. En las notas previas de su ensayo Du lyrisme, Jean-Michel Maulpoix escribe: «El lirismo es la voz de un individuo a quien la experiencia infinita del lenguaje recuerda su situación de exiliado en el mundo, y simultáneamente le permite afincarse en él, como si se adentrara gracias a ella en el corazón del enigma que le plantea su propia condición» (2000: 14; la traducción es nuestra). Por ser una cuestión esencial, Ángel González nunca pierde de vista esta temática, evocada de nuevo en Otoños y otras luces en el poema "Aquí y allí»: 
El efecto de distanciamiento producido por los guiones puede recaer en la opinión que avanza el poeta a propósito de situaciones vividas, aparentemente halagüeñas, pero cuyo envés merece sus sarcasmos. Así ocurre con el retrato que Ángel González deja de «los indianos de [su] infancia»:

Regalaban también brillantes cálices
de oro a las iglesias,
coronas refulgentes a las vírgenes
de madera, y valiosas monedas
a las vírgenes otras: las de carne
—en cuya piel se demostraba cómo,
contra lo que pudiera suponerse,
hay cosas que mejora
la dieta anteriormente reseñada-.
Exhibían el oro en su sonrisa
(irresistible cuanto más dorada)
y se morían casi siempre pronto
(González, 1986: 231).

Lo expresado entre guiones pone a plena luz la hipocresía y el soborno de indianos amables que compraban el favor de jóvenes doncellas. El juicio en este caso está al servicio del humor y se entiende con lo dicho anteriormente. De modo que Ángel González conserva intacto lo narrativo. Los guiones, como el paréntesis de este mismo texto, marcan el cambio de perspectiva para adoptar una postura humorística. El rasgo de humor se había iniciado antes a través de la oposición "de madera» / "de carne»: «Regalaban también brillantes cálices / de oro a las iglesias, / coronas refulgentes a las vírgenes / de madera, y valiosas monedas / a las vírgenes otras: las de carne». "[Dar] monedas / a las vírgenes [...] de carne» viene a ser un gesto equívoco. El lector entiende que no se trata de una manifestación bondadosa ni caritativa, sino de comprar un servicio sexual (al significado literal se superpone un significado intencional). Ahora bien, para elevar al máximo la crítica social,Ángel González se deja llevar por una extensión del discurso cuyo enunciado complejo

«Quién es el que está aquí, y dónde: / ¿dentro o fuera? // ¿Soy yo el que siente y el que da sentido / al mundo? / ¿O es el secreto corazón del mundo / —remoto, inaccesible- / el que me da sentido a mí? // Qué lejos siempre entonces ya de todo, / incluso de mí mismo; / qué solo y qué perdido yo, / aquí o allí» (2001:23). 
coloca entre guiones, provocando así una saturación del texto por el significante: "hay cosas que mejora la dieta anteriormente reseñada», dieta que remite al «hambre que les había expulsado cuando niños». El paréntesis que viene a continuación desempeña el mismo papel de presentar amablemente un caso lamentable: «Exhibían el oro en su sonrisa / (irresistible cuanto más dorada)». La intervención del enunciador en su relato sirve para hacer sospechoso y engañoso el poder del dinero.

Sucede lo mismo con la mirada mordaz de un humor que roza la ironía en el poema «Zona residencial», donde Ángel González acude a los paréntesis para consignar detalles accesorios dentro del esquema narrativo de un texto abocado al elogio aparente de la «zona residencial», compendio de los éxitos del desarrollismo de los años sesenta (Tratado de urbanismo se publicó en 1967). Los comentarios parentéticos, "pertinentes para la visión del poeta» (Alarcos Llorach 1969: 109), forman bloques de texto que constituyen el significado esencial de la intención del poeta:

$[\ldots]$

la perfección reside en estas calles.

$[\ldots]$

eso que la mirada

comprueba

en las palomas viandantes

$[\ldots]$

en las personas y sus atributos:

niños

(bicicletas y risas niqueladas),

militares

(de alta graduación, sin sable

ni escopetas, solo

con artritismo y condecoraciones),

adolescentes

(de agradable formato, encuadernados

en piel de calidad insuperable), 
doncellas

(del servicio doméstico

- se entiende-

también bellas debajo de la cofia)

(González, 1986: 198).

Aquí, la técnica parentética construye un ritmo, ya que las realidades observadas (niños, militares, adolescentes, doncellas...) o los vecinos de la zona residencial forman los significantes individualizados en versos breves prolongados por los incisos del enunciador «ironista», que facilita indicios para que el lector busque la intención del autor. La descodificación del significado intencional, en la medida en que acierta, permite cuestionar la ilusión optimista del desarrollismo y la falsedad de «los 25 años de paz».

A nivel formal, es de notar que los paréntesis en este caso crean más una continuidad que una ruptura; el enunciado entre paréntesis completa el sustantivo aislado al principio de la estrofa, lo prolonga colocándolo en la temporalidad del enunciador. Así, a la armonía superficial del mundo exterior, captada linealmente, se superpone el discurso interiorizado de incisos que enseñan el envés de la pantalla, la dualidad antagónica entre las apariencias y la realidad social más profunda.

La experiencia del vacío existencial y lo absurdo de una vida sin perspectiva es un tema recurrente en Ángel González, y el poeta sabe cultivar la extrañeza mediante la ambigüedad sintáctica, derivada de cierta concatenación inesperada, como en «Meriendo algunas tardes»:

Meriendo algunas tardes:

no todas tienen pulpa comestible.

Si estoy junto a la mar muerdo primero los acantilados, luego las nubes cárdenas y el cielo

- escupo las gaviotas-,

y para postre dejo las bañistas

jugando a la pelota y despeinadas.

Si estoy en la ciudad

meriendo tarde a secas:

mastico lentamente los minutos

— tras haberles quitado las espinas- 
y cuando se me acaban

me voy rumiando sombras, rememorando el tiempo devorado con un acre sabor a nada en la garganta (González, 1986: 240).

La incompatibilidad semántica no aparece inmediatamente, ya que en el primer verso la referencia temporal de "algunas tardes» resulta posible, pero con el verso siguiente se inicia una formulación extraña que pone al lector ante una inverosimilitud aceptable («no todas tienen pulpa comestible»), en la medida en que el poeta mantiene una coherencia dentro de la alogicidad. Sigue con la misma isotopía de una «merienda» con ingredientes imposibles: «muerdo primero los acantilados, / luego las nubes cárdenas». Ahora bien, ¿qué interés tienen los enunciados entre guiones si no hacen más que continuar la alogicidad del discurso principal? Lo incluido entre guiones («—escupo las gaviotas- / [...] mastico lentamente los minutos / - tras haberles quitado las espinas—》) permite el rebote humorístico imprescindible, este guiño que asocia al lector con el juego de la disyunción semántica, aceptada con la suspensión del juicio. Los sintagmas entre paréntesis coinciden con el paroxismo de lo cómico, recalcan la complicidad entre autor y lector hasta que ambos compartan la misma sensación de lo absurdo y tengan el mismo "acre sabor a nada en la garganta».

Resulta bastante difícil establecer una tipología del uso de los guiones o paréntesis a partir de criterios de funcionalidad, ya que tal uso es polivalente y está determinado por el contexto lingüístico de cada poema. Quizá una aproximación satisfactoria, por su grado de generalidad, sería la derivada del efecto rítmico, como apunta Lucie Lavergne en su estudio Espaces et rythmes en poésie:

La presencia de estos signos de puntuación [guiones y paréntesis] puede generar dos tipos de construcciones rítmicas, según predomine la ruptura entre el inciso y el resto de la oración, o la continuidad. Así el ritmo reside ya en el choque, ya en la relación de las voces en presencia (2014: 149).

En los ejemplos estudiados hasta ahora, hemos podido observar que tales recursos permitían siempre una variación de los puntos de vista sobre el enunciado y contribuían a la polisemia del discurso poético en general. Comentaremos a continuación un caso de 
inversión del pensamiento, cuyo mecanismo se arma en los paréntesis, especialmente aquellos en los que el sujeto nos hace testigos de su propia construcción. Gran parte de la filosofia gonzaliana está cifrada en el sintagma antitético Sin esperanza, con convencimiento. Esta frase resume el principio de negatividad que opera en todo el poema «Del campo o de la mar»:

Huimos con nuestros enseres y nos dispersamos por los campos, buscando preferentemente las orillas del mar y de los ríos.

(Dejamos atrás la desolación, el sufrimiento, la ciudad desierta y calcinada.)

[...]

dejábamos que el tiempo planease sobre nuestras cabezas

- tenaz y lento como un buitre-

nuestra futura destrucción, quizá inminente.

Thelonius Monk,Vivaldi y otros monstruos

nos roían las entrañas, percutían

en nuestras vísceras, colmaban

los cuerpos de deseo, de sed de alcohol, de angustia por las tardes, y la noche nos expulsaba con violencia fuera de nuestros refugios. Impulsados por algo parecido al miedo, acudíamos entonces en busca de otros rostros, gentes de todo el mundo compartían nuestra urgencia, acosados por ritmos y canciones —el rock igual que un látigo cruzándonos el pecho-, donde quiera que fueras Bob Dylan te encontraba (González, 1986: 249).

El sentido literal se deja comprender fácilmente. Se trata de romper el tedio y el aburrimiento de la semana; la llegada del fin de semana o del veraneo significa la posibilidad de vivir un tiempo ebrio de libertad y goce a toda prisa. El inciso, con su imagen violenta, abre el lapso en que se huye de la opresión. Pero sería un reduccionismo total considerar la temática del tiempo en la poesía contemporánea como simple representación del desgaste humano o el hastío ante una organización social opresiva y sin perspectiva. El atractivo de la música en Ángel González es algo más que una escapatoria: corresponde a un ensanchamiento del yo, una manera de romper los diques del inmovilismo y construir su propia identidad en el flujo de los acontecimientos. Por eso, Ángel González ve en la música, aunque esta solo coincidiera con un lapso efimero, una vía para colmar el vacío, un flujo que le quita gravidez a la adversidad. 
Lo dicho entre guiones participa en la apertura del yo, que se siente arrebatado por los impulsos de la vida, oscilando entre el orden y el desorden, la resignación y la voluntad. La devoración sugerida por la imagen del «buitre» o la reacción al «látigo del rock» no se evalúan negativamente, sino que simbolizan la vuelta a un mundo que nunca se deja inmovilizar en un orden de objetos estables. Podría sorprender el final aparentemente pesimista del poema: «Estábamos seguros de que todo era inútil, / mirarse, sonreír, hablar incluso, / besar, amar, nada nos salvaría». Sin embargo, esta evasión hacia «el campo o la mar», asimilable a una ensoñación, a medio camino entre el sueño (huida fuera del tiempo) y la vigilia (voluntad de rescatar algo del deseo de transformación), se resuelve en Ángel González en la representación de lo discontinuo: oposiciones, rupturas, alteraciones afectivas o existenciales, que tienen sus equivalentes en el fraseo sintagmático articulado con signos de puntuación que avalan la necesaria continuidad del ser. El «—no había donde sentarse-» posterior no puede tomarse al pie de la letra, sino que es la expresión de un yo infinito que busca en el fluir de la vida o de la escritura lo que merece ser representado.

Repetidas veces hemos dicho que los signos gráficos que salpican los poemas de Ángel González contribuyen a crear un ritmo, ya que se regula la organización sintáctica del texto, desvinculado la mayoría de las veces de la métrica convencional (las sílabas contadas con sus períodos y cláusulas) y de las sonoridades de la rima, admitido que este tipo de prosodia está al servicio de un significado predeterminado. Con la poesía moderna, la prosodia es cambiante, aleatoria, sentido y sonido mantienen la connivencia o bien entran en conflicto, y la vuelta a un posible cratilismo se apoya en todos los recursos no solo fónicos, sino también visuales, ya que el grafismo de los sangrados, los versos escalonados y los signos de puntuación también define el pulso del poema. A pesar de que Ángel González se ciñe a un lenguaje liso, sin ornamentación superflua, pero en el que la sencillez es solo aparente, consigue por su inventiva reducir la arbitrariedad del signo. Como el Crátilo de Platón, la relación que Ángel González mantiene con el lenguaje consiste en abonar, mediante una serie de procedimientos estilísticos, retóricos y rítmicos, la referencialidad al mundo. El ambiente poético así creado surge de las relaciones que la materialidad del texto establece con el universo «real». Cuando hablamos de adecuación entre la forma y el contenido, quiere decirse que el poeta está condenado a repetir la 
búsqueda de la lengua exacta. Con este esfuerzo frustrado es como paradójicamente se mantiene la palabra en vilo.

El estudio de ciertos aspectos del poema «La palabra» puede ayudarnos a comprender el enigma. En esta composición, Ángel González superpone tres relatos: la contemplación de un paisaje domesticado por la actividad humana, el nacimiento del lenguaje articulado y por último, en cursiva, su transformación en voz poemática. Tal recorrido, que va desde la percepción visual o emotiva hasta su fijación mediante la escritura, describe la labor del poeta en su deseo de ahormar una lengua. Los momentos de esta reflexión que se apoyan en un referente concreto elevan el debate a un nivel teórico cuyos puntos de intersección están marcados por los enunciados entre paréntesis. Así, la primera etapa coincide con el surgimiento de la primera palabra humana ante un paisaje:

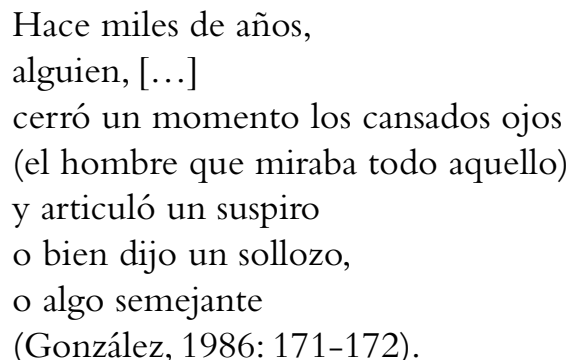

Más de treinta versos, incluyendo dos incisos largos con oraciones complejas, separan el sujeto gramatical del verbo principal, "articuló un suspiro", para mimetizar el tiempo milenario durante el cual se desarrolló el lenguaje. Historia abreviada, y acaso hipotética, de una evolución que arroja luz sobre la existencia misma de la poesía. En el origen del lenguaje, se supone la emisión de apenas un grito, «un suspiro, un sollozo», solo el deseo de comunicar algo; o sea, la necesidad socializada empujó al individuo a perfeccionar el mecanismo de una lengua puramente instrumental, olvidando que en su origen tenía el poder de manifestar la presencia de los objetos. Nombrar tal o cual flor, árbol o pájaro no consiste en designar el objeto real, sino en provocar la llegada de cualquier objeto perceptible. Semejante capacidad de la palabra se manifiesta plenamente en el decir poético. La palabra poética plantea en nuestra proximidad solo la sombra de las cosas del mundo. Por lo tanto, el poeta tiende a restituir la plenitud nativa de las palabras: la poesía es esta capacidad apofántica de llenar lo ausente. Esta forma de negatividad del decir 
poético está magníficamente evocada a través del temblor «de la rama / abandonada de un pájaro...».

Para evidenciar el efecto de la palabra poética, Ángel González se sirve del verso escalonado y pone en cursiva, aislada en el centro del poema la palabra «amor»:

surgió en el aire limpio de aquel día

la palabra:

amor.

Era

suficiente

(González, 1986: 172).

No es una casualidad que el poeta haya escogido esta palabra, «amor», como núcleo de intensidad del lenguaje. De sobra sabemos todos que el amor no es una temática ordinaria, sino un resorte inagotable que propició a los poetas la escala de los estados anímicos a partir de la cual la poesía ajusta sus tonalidades afectivas. Palabra de plenitud que supone que la escritura poética convierte la lengua en objeto de deseo. No faltan en la obra de Ángel González las metáforas que erotizan el acto de escribir remitiendo la palabra «amor» a su origen corpóreo.Ya insistió Bénédicte Mathios sobre este punto en el análisis que hizo de este poema (2009: 214-218). Pero lo que la profesora no dice es que la voz sonora se ha transformado en voz silenciosa, fijación que amenaza la palabra con el riesgo de cerrarla en sus significaciones. La labor del poeta consiste en frenar esta asfixia de las lenguas contaminadas por «el universal reportaje», según la expresión de Mallarmé. Intentando definir el misterio de la poesía, Christian Prigent, poeta y teórico de la expresión poética, escribe: «la poesía se dice en un aliento, o sea en lo que empuja delante de nosotros las figuras del mundo: las pulveriza, deshace sus contornos codificados, les facilita nuevo pase y vida nueva» (2004: 38). Ángel González adopta una actitud similar usando la misma metáfora del aliento:

la elijo entre otras muchas,

Yo la recojo [la palabra],

la empaño con mi aliento y la lanzo,

pájaro o piedra,

de nuevo al aire,

al sol, 
hoy

(rostros, árboles,

nubes: todo es distinto en esta primavera. En el vaso, el agua huele a río. [...])

(González, 1986: 173).

Mediante el recurso del verso escalonado, Ángel González «avienta» la palabra o, si queremos, pretende salvarla de la anquilosis de los significados, resistir contra todo lo que coagula el sentido y la forma. Por eso, se interesa por las pulsaciones no figurativas de la lengua (por ejemplo, el significante fónico y sus ecolalias), busca un fraseo abstracto; no una armonía, sino un compás que nos descubra las primeras sensaciones del mundo. Así prolonga, en una especie de añadido en cursiva y entre paréntesis, un decir que repristina el valor de la palabra poética, a sabiendas de que la voz personal se hace oír entre tanteos, en el flujo voluptuoso y dolido de las significaciones:

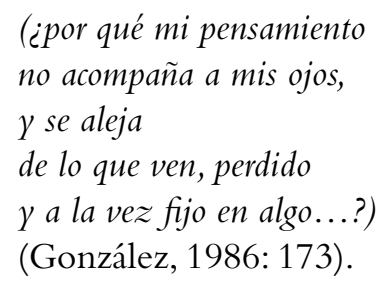

Ángel González cierra el poema con una pregunta que contempla la dinámica del código, esta energía que define la poesía: un discurso que fluye entre un puro "fuera de sentido" (musicalidad y ritmo) y un sentido ahormado (mimesis y expresividad), apuntalado por la voluntad de estilo: "porque quiero».

Los fenómenos o recursos (visuales los más) que acabamos de analizar en los poemas de Ángel González ponen de relieve una falsa oposición entre la voz y la escritura, en el sentido barthesiano de la palabra. Voz y escritura no son antagonistas, sino que se respaldan desde un empuje gramatológico que vertebra el texto, recordándonos que el lenguaje poético siempre actualiza una mediación y que el poema hace de esta mediación misma el resorte de su intencionalidad. 


\section{BIBLIOGRAFÍA}

Alarcos Llorach, Emilio (1996). La poesía de Ángel González, Oviedo, Nobel.

Aquien, Michèle (1997). L'autre versant du langage, Paris, José Corti.

Areta Marigó, Gema, Hervé le Corre, Modesta Suárez y Daniel Vives (eds.) (2000). Poesía hispanoamericana: ritmo(s) / métrica(s) / ruptura(s), Madrid,Verbum.

Baena, Enrique (1990). «La imagen poética de la experiencia: ironía y humor en Ángel González», Anthropos [«Ángel González. Una poética de la experiencia y la cotidianidad»], 109, pp. 104-109.

DAydí-Tolson, Santiago (1988-1989). «Oralidad y escritura en la poesía de Ángel González», Siglo XX / 20 th Century, 6, pp. 1-10.

Ferrari, Marta B. (2001). «El otro lado del poema. La antipoesía de Ángel González», en La coartada metapoética, Mar del Plata, Editorial Martin, pp. 129-168.

GonzÁlez, Ángel (1986). Palabra sobre palabra, Barcelona, Seix Barral.

- (2001). Otoños y otras luces, Barcelona, Tusquets.

LAVERGNe, Lucie (2014). Espaces et rythmes en poésie. Six visages de la poésie hispanophone du XXe siècle, Paris, L'Harmattan.

Le Bigot, Claude (2014). «¿Fue Ángel González un poeta posmoderno?: examen de su antipoesía», Prosemas. Revista de Estudios Poéticos, 1, pp. 111-126.

— (2016). «El antipoema: ruptura del código en la poesía chilena, española y francesa de los siglos XX-XXI», Mapocho. Revista de Humanidades, 76, pp. 115-139.

Mathios, Bénédicte (2009). Une lecture de l'ouvre d'Ángel

González: corps et écriture poétique, Berne, Peter Lang.

Maulpoix, Jean-Michel (2000). Du lyrisme, Paris, José Corti.

- (2018). Les 100 mots de la poésie, Paris, PUF.

PARAíso, Isabel (1985). El verso libre hispánico, Madrid, Gredos.

Prado, Benjamín (2008). «Ángel González, la coherencia en sílabas contadas», Cuadernos Hispanoamericanos [«Los Complementarios. Ángel González»], Extra 17, pp. 56-60.

Prieto de Paula, Ángel L. (2016). «Los sonetos heterodoxos de Ángel González», en Ángel, me dicen. Actas de las I Jornadas académicas sobre Ángel González y su generación poética celebradas en Oviedo del 2 al 4 de diciembre de 2015, ed. Araceli Iravedra, Oviedo, Universidad de Oviedo, pp. 79-96.

Prigent, Christian (2004). L'Incontenable, Paris, P.O.L. 
Romano, Marcela (2003). Almas en borrador. Sobre la poesía de Ángel González y Jaime Gil de Biedma, Mar del Plata, Editorial Martin.

SÁnchez Torre, Leopoldo (2005). «La inversión de los géneros discursivos en Grado elemental, de Ángel González», Zurgai, junio, pp. 98-103.

Sobejano, Gonzalo (1987). «Salvación de la prosa, belleza de la necesidad en la poesía de Ángel González», en Simposio-Homenaje a Ángel González, eds. Susana Rivera y Tomás Ruiz Fábrega, Madrid, José Esteban, pp. 21-54.

— (1991). «Un prosema de Ángel González, más ciertas precisiones», en En homenaje a Ángel González: ensayos, entrevista, poemas, eds. Andrew P. Debicki y Sharon Keefe Ugalde, Boulder, University of Colorado, pp. 85-96.

Spang, Kurt (1993). Análisis métrico, Pamplona, Eunsa. 